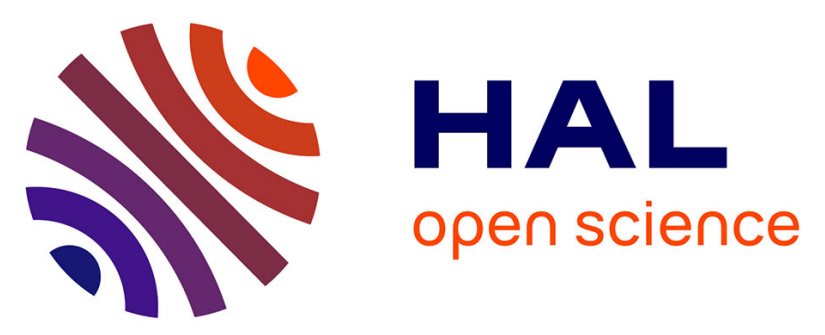

\title{
Mutations in XPR1 cause primary familial brain calcification associated with altered phosphate export
}

Andrea Legati, Donatella Giovannini, Gaël Nicolas, Uriel López-Sánchez, Beatriz Quintáns, João R M Oliveira, Renee L Sears, Eliana Marisa Ramos, Elizabeth Spiteri, Maria-Jesus Sobrido, et al.

\section{To cite this version:}

Andrea Legati, Donatella Giovannini, Gaël Nicolas, Uriel López-Sánchez, Beatriz Quintáns, et al.. Mutations in XPR1 cause primary familial brain calcification associated with altered phosphate export. Nature Genetics, 2015, 47 (6), pp.579-581. 10.1038/ng.3289 hal-02109489

\section{HAL Id: hal-02109489 \\ https://hal.science/hal-02109489}

Submitted on 23 Jul 2019

HAL is a multi-disciplinary open access archive for the deposit and dissemination of scientific research documents, whether they are published or not. The documents may come from teaching and research institutions in France or abroad, or from public or private research centers.
L'archive ouverte pluridisciplinaire HAL, est destinée au dépôt et à la diffusion de documents scientifiques de niveau recherche, publiés ou non, émanant des établissements d'enseignement et de recherche français ou étrangers, des laboratoires publics ou privés. 


\section{Mutations in XPR1 cause primary familial brain calcification associated with altered phosphate export}

\author{
Andrea Legati ${ }^{1,34}$, Donatella Giovannini ${ }^{2-5,34}$, Gaël Nicolas ${ }^{6-8}$, \\ Uriel López-Sánchez ${ }^{2-5}$, Beatriz Quintáns ${ }^{9,10}$, João R M Oliveira ${ }^{11}$, \\ Renee L Sears ${ }^{1,33}$, Eliana Marisa Ramos ${ }^{1}$, Elizabeth Spiteri ${ }^{12,33}$, \\ María-Jesús Sobrido ${ }^{9,10}$, Ángel Carracedo ${ }^{9,10}$, \\ Cristina Castro-Fernández ${ }^{9,10}$, Stéphanie Cubizolle ${ }^{13}$, \\ Brent L Fogel $^{12}$, Cyril Goizet ${ }^{14}$, Joanna C Jen ${ }^{12}$, Suppachok Kirdlarp ${ }^{15}$, \\ Anthony E Lang ${ }^{16,17}$, Zosia Miedzybrodzka ${ }^{18}$, Witoon Mitarnun ${ }^{15}$, \\ Martin Paucar ${ }^{19,20}$, Henry Paulson ${ }^{21}$, Jérémie Pariente ${ }^{22,23}$, \\ Anne-Claire Richard ${ }^{6,7}$, Naomi S Salins ${ }^{24}$, Sheila A Simpson ${ }^{18}$, \\ Pasquale Striano ${ }^{25}$, Per Svenningsson ${ }^{19,20}$, François Tison ${ }^{13}$, \\ Vivek K Unni $^{26}$, Olivier Vanakker ${ }^{27}$, Marja W Wessels ${ }^{28}$, \\ Suppachok Wetchaphanphesat ${ }^{15}$, Michele Yang ${ }^{29}$, Francois Boller ${ }^{30}$, \\ Dominique Campion $^{6,7,31}$, Didier Hannequin ${ }^{6-8,32}$, Marc Sitbon $^{2-5}$, \\ Daniel H Geschwind ${ }^{1,12}$, Jean-Luc Battini ${ }^{2-5}$ \& Giovanni Coppola ${ }^{1,12}$
}

Primary familial brain calcification (PFBC) is a neurological disease characterized by calcium phosphate deposits in the basal ganglia and other brain regions and has thus far been associated with SLC20A2, PDGFB or PDGFRB mutations. We identified in multiple families with PFBC mutations in XPR1, a gene encoding a retroviral receptor with phosphate export function. These mutations alter phosphate export, implicating $X P R 1$ and phosphate homeostasis in PFBC.

PFBC, also known as idiopathic basal ganglia calcification or Fahr's disease, is a rare, clinically heterogeneous neurodegenerative disorder ${ }^{1}$. PFBC symptoms typically occur after the age of 40 years with progressive neuropsychiatric and movement disorders, although some individuals may remain asymptomatic. Clinical features include dystonia, parkinsonism, ataxia, psychosis, dementia, chorea and frontal-subcortical cognitive dysfunction. Bilateral calcifications of the basal ganglia are visualized on computed tomography (CT scans). PFBC is genetically heterogeneous, typically inherited in an autosomal dominant fashion. Causative mutations have been found in SLC20A2 (refs. 2,3), which encodes the phosphate transporter PiT2 (ref. 4), in $P D G F R B^{5}$, which encodes platelet-derived growth factor receptor $\beta$ (PDGFR $\beta$ ), and in $P D G F B^{6}$, which encodes the PDGFR $\beta$ ligand. Altogether, mutations in these three genes account for $49 \%$ of families with PFBC in our cohort ${ }^{3}$.

We evaluated a North American family of Swedish ancestry with $\mathrm{PFBC}^{7}$ lacking mutations in SLC20A2, PDGFB and PDGFRB. Our analysis included 17 members ( 9 affected, 3 unaffected and 5 of unknown status; Supplementary Fig. 1a). When assessed, the clinical presentation consisted of dementia, speech impairment (slurred speech, palilalia), chorea and unsteady gait (Supplementary Table 1) ${ }^{8}$. CT scans of the brain showed extensive intracranial calcifications in basal ganglia extending to the cerebral cortex or cerebellum.

We performed exome sequencing in four affected family members (III-4, III-5, III-9 and IV-6) and in one unaffected family member (II-5). We identified a total of 83,848 variants in these 5 samples (Supplementary Fig. 1b). First, we filtered out variants present in dbSNP138 and present with frequency $>1 \%$ in the 1000 Genomes Project and Exome Variant Server databases. We then focused on missense, splice-site, stop-gain or stoploss, and frameshift variants. Seven variants (Supplementary Table 2) segregated with the disease in these 5 samples and were assessed in all 17 available family members using Sanger sequencing. Only one variant was present in all affected individuals and absent from unaffected family members (maximum logarithm of odds (LOD) score of 3.6):

${ }^{1}$ Department of Psychiatry, David Geffen School of Medicine, University of California, Los Angeles, Los Angeles, California, USA. ${ }^{2}$ Institut de Génétique Moléculaire de Montpellier, CNRS UMR 5535, Montpellier, France. ${ }^{3}$ Université de Montpellier, Montpellier, France. ${ }^{4}$ Laboratory of Excellence GR-Ex, Paris, France. ${ }^{5}$ Laboratory of Excellence EpiGenMed, Montpellier, France. 6INSERM U1079, Institute for Research and Innovation in Biomedicine (IRIB), University of Rouen, Rouen, France. ${ }^{7}$ Centre National de Référence pour les Malades Alzheimer Jeunes (CNR-MAJ), Rouen University Hospital, Rouen, France. ${ }^{8}$ Department of Genetics, Rouen University Hospital, Rouen, France. ${ }^{9}$ Fundación Pública Galega de Medicina Xenómica, Servizo Galego de Saúde (SERGAS), Instituto de Investigación Sanitaria (IDIS, Hospital Clínico Universitario), Santiago de Compostela, Spain. ${ }^{10} \mathrm{Grupo}$ de Medicina Xenómica, Centro de Investigación Biomédica en Red de Enfermedades Raras (CIBERER, Universidad de Santiago de Compostela), Santiago de Compostela, Spain. ${ }^{11}$ Keizo Asami Laboratory, Federal University of Pernambuco, Recife, Brazil. ${ }^{12}$ Department of Neurology, David Geffen School of Medicine, University of California, Los Angeles, Los Angeles, California, USA. ${ }^{13 N e u r o l o g y}$ and Institute for Neurodegenerative Diseases, Bordeaux University Hospital and Bordeaux University, Bordeaux, France. ${ }^{14}$ Service de Génétique Médicale, Bordeaux Hospital University Center, Bordeaux, France. ${ }^{15}$ Division of Medicine, Buriram Hospital, Buriram, Thailand. ${ }^{16}$ Morton and Gloria Movement Disorders Clinic, Toronto Western Hospital, Toronto, Ontario, Canada. ${ }^{17}$ Edmond J. Safra Program in Parkinson's Disease, Toronto Western Hospital, Toronto, Ontario, Canada. ${ }^{18}$ Medical Genetics Group, School of Medicine and Dentistry, University of Aberdeen, Aberdeen, UK. ${ }^{19}$ Translational Neuropharmacology, Clinical Neuroscience, Center for Molecular Medicine, Karolinska Institute, Stockholm, Sweden. ${ }^{20}$ Department of Neurology, Karolinska University Hospital Huddinge, Stockholm, Sweden. ${ }^{21}$ Department of Neurology, University of Michigan, Ann Arbor, Michigan, USA. 22INSERM, Imagerie Cérébrale et Handicaps Neurologiques, UMR 825, Pole Neurosciences, Centre Hospitalier Universitaire (CHU) Purpan, Toulouse, France. ${ }^{23} \mathrm{CHU}$ de Toulouse, Université de Toulouse, Toulouse, France. ${ }^{24}$ Barrow Neurological Institute, Phoenix, Arizona, USA. ${ }^{25}$ Pediatric Neurology and Muscular Diseases Unit, Department of Neurosciences, Rehabilitation, Ophthalmology, Genetics, and Maternal and Child Health, University of Genoa 'G. Gaslini' Institute, Genoa, Italy. ${ }^{26}$ Department of Neurology, Oregon Health and Science University, Portland, Oregon, USA. ${ }^{27}$ Center for Medical Genetics, Ghent University Hospital, Ghent, Belgium. ${ }^{28}$ Department of Clinical Genetics, Erasmus Medical Center, Rotterdam, the Netherlands. ${ }^{29}$ Department of Pediatrics, Children's Hospital Colorado and University of Colorado Denver, Aurora, Colorado, USA. ${ }^{30}$ Department of Neurology, George Washington University Medical School, Washington, DC, USA. ${ }^{31}$ Department of Research, Rouvray Psychiatric Hospital, Sotteville-lès-Rouen, France. ${ }^{32}$ Department of Neurology, Rouen University Hospital, Rouen, France.

${ }^{33}$ Present addresses: Department of Genetics, Center for Genome Sciences and Systems Biology, Washington University School of Medicine, St. Louis, Missouri, USA (R.L.S.) and Kaiser Permanente Southern California Permanente Medical Group, Regional Reference Laboratories, Genetics Laboratory, Los Angeles, California, USA (E.S.). ${ }^{34}$ These authors contributed equally to this work. Correspondence should be addressed to J.-L.B. (jean-luc.battini@igmm.cnrs.fr) or G.C. (gcoppola@ucla.edu). 
a

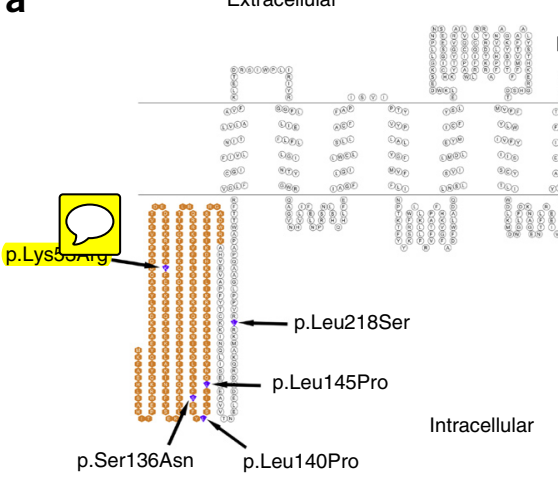

Extracellular

Figure 1 Localization of the identified variants in the XPR 1 protein and effect of p.Leu145Pro on protein expression and function. (a) Schematic of the XPR1 protein and the variants identified in this study. The SPX domain is in orange. (b) Efflux of inorganic ${ }^{33} P\left(P_{\mathrm{i}}\right)$ in HEK293T cells transfected with control siRNA to luciferase (siLUC; lane 1), SiRNA to XPR1 (siXPR1) alone (lane 2), or siRNA to XPR1 in combination with vector expressing HA-tagged wild-type (lane 3 ) or Leu145Pro (lane 4) human XPR1. Results are means \pm s.e.m. in a representative experiment $(n=3) ;{ }^{*} P \leq 0.01,{ }^{* * *} P \leq 0.001$ as tested against the luciferasetargeting siRNA control. (c) Immunoblot of HA-tagged XPR1 expression in cell lysates with an antibody to HA (top). $\beta$-actin was used as loading control (bottom). (d) Cell surface detection of XPR1 on HEK293T cells transfected as in b. Nonspecific staining with the secondary IgG antibody (filled histogram) and specific binding with the X-MLV receptor-binding domain (RBD) (unfilled histogram) are represented. Numbers indicate the specific mean fluorescence intensity of a representative experiment $(n=3)$. (e) Efflux of ${ }^{33} \mathrm{P}$ in PBMCs collected from two control healthy donors (circles or squares) and two affected patients harboring the p.Leu145Pro alteration (triangles pointing up or down). Bars represent means \pm s.e.m.; ${ }^{* *} P \leq 0.001$.

a c.434T >C transition in the mammalian XPR1 gene (NM_004736.3; encoding xenotropic and polytropic retrovirus receptor 1), predicted to result in a deleterious p.Leu145Pro alteration at a highly conserved residue within the SPX domain shared by SYG1/PHO81/XPR1 proteins ${ }^{9}$ (Fig. 1a) and absent from repositories of sequence variation, including the Exome Aggregation Consortium (ExAC) database.

Further sequencing of XPR 1 in 86 additional sporadic and familial cases identified the same p.Leu145Pro variant in two affected individuals from a family of French descent and five additional missense variants. Pedigree analyses and the segregation patterns of variants surrounding XPR1 suggested that the two families carrying the p.Leu145Pro variant were not related (Online Methods). Three other variants, p.Ser136Asn, p.Leu140Pro and p.Leu218Ser (Fig. 1a, Table 1, Supplementary Fig. 2 and Supplementary Table 3), all located in the SPX domain or in its vicinity and predicted to be damaging, were absent from variation repositories. The p.Lys53Arg variant, also absent from variation databases, is predicted to be non-damaging. The p.Ile575Val variant has a minor allele frequency of $0.068 \%$ in ExAC, interchanges two hydrophobic residues in a transmembrane domain and is likely to represent a rare polymorphism. None of these variants were found in two in-house series (126 French and 161 North American controls of European ancestry screened with exome sequencing and targeted resequencing, respectively).

$\mathrm{XPR} 1$ is a cell surface multipass membrane protein initially identified as the mammalian receptor for xenotropic murine leukemia viruses $(\mathrm{X}-\mathrm{MLV})^{9,10}$. It contains an $\mathrm{N}$-terminal SPX domain (Fig. 1a) that is also found in several yeast and plant proteins involved in phosphate homeostasis ${ }^{11,12}$. We have recently shown that XPR1 mediates phosphate export ${ }^{13}$, a function that is highly conserved across evolution ${ }^{13,14}$. We tested all the newly identified XPR1 variants in a complementation assay for phosphate efflux in human cells $^{13}$, wherein phosphate efflux decreased after the introduction of XPR1-targeting small interfering siRNA (siRNA) but was restored by the expression of wild-type or mutant XPR1 (Fig. 1b). We found that Leu145Pro mutant XPR1 neither reestablished phosphate efflux nor served as the receptor for X-MLV during infection (Fig. 1 b and Supplementary Table 4). Consistent with this observation, phosphate efflux was also impaired in the peripheral blood mononuclear cells (PBMCs) isolated from the two patients harboring the p.Leu145Pro alteration that we tested (Fig. 1e). This substitution affected cell surface exposure of XPR1 on HEK293T cells, as monitored by flow cytometry with an XPR1 ligand (XRBD) derived from the X-MLV envelope glycoprotein ${ }^{13}$, although the expression levels of Leu145Pro XPR1 remained substantial (Fig. 1c,d). Remarkably, expression of Leu145Pro XPR1 specifically decreased the phosphate efflux of endogenous XPR1 (Fig. 1b), whereas we observed no effect on the expression of the phosphate importers PiT1 and PiT2 or on phosphate uptake (Supplementary Fig. 3), supporting a trans dominant-negative effect of the Leu145Pro mutant on wild-type XPR1. In contrast, the four other mutants were present at the plasma membrane and served as potent retroviral receptors (Supplementary Fig. 4 and Supplementary Table 4). The three variants p.Ser136Asn, p.Leu140Pro and p.Leu218Ser all affected XPR1

Table 1 Rare XPR1 variants identified in the index proband and a follow-up cohort of 86 index cases

\begin{tabular}{|c|c|c|c|c|c|c|c|c|c|c|}
\hline Genomic position & cDNA & Protein & $\begin{array}{l}\text { PolyPhen-2 } \\
\text { function } \\
\text { prediction }\end{array}$ & $\begin{array}{c}\text { SIFT } \\
\text { function } \\
\text { prediction }\end{array}$ & $\begin{array}{c}\text { MutationTaster } \\
\text { function } \\
\text { prediction }\end{array}$ & dbSNP ID & $\begin{array}{c}1000 \\
\text { Genomes } \\
\text { frequency }\end{array}$ & $\begin{array}{l}\text { NHLBI } \\
\text { EVS } \\
\text { frequency }\end{array}$ & $\begin{array}{c}\text { ExAC } \\
\text { allelic } \\
\text { frequency }\end{array}$ & GERP \\
\hline Chr. 1: $180,756,925$ & c. $158 \mathrm{~A}>\mathrm{G}$ & p.Lys53Arg & Benign & Tolerated & Disease causing & - & Absent & Absent & Absent & 5 \\
\hline Chr. 1: $180,772,707$ & c. $407 \mathrm{G}>\mathrm{A}$ & p.Ser136Asn & Probably damaging & Damaging & Disease causing & _- & Absent & Absent & Absent & 5.93 \\
\hline Chr. 1: $180,772,719$ & c. $419 \mathrm{~T}>\mathrm{C}$ & p.Leu140Pro & Probably damaging & Damaging & Disease causing & - & Absent & Absent & Absent & 5.93 \\
\hline Chr. 1: $180,772,734$ & c. $434 \mathrm{~T}>\mathrm{C}$ & p.Leu145Pro & Probably damaging & Damaging & Disease causing & - & Absent & Absent & Absent & 5.93 \\
\hline Chr. 1: 180,775,665 & c.653T>C & p.Leu218Ser & Probably damaging & Damaging & Disease causing & - & Absent & Absent & Absent & 5.15 \\
\hline Chr. 1: $180,842,993$ & c. $1723 \mathrm{~A}>\mathrm{G}$ & p.lle575Val & Benign & Tolerated & Disease causing & rs147941113 & $0.040 \%$ & $0.054 \%$ & $\begin{array}{c}83 / 121,330 \\
(0.068 \%)\end{array}$ & 2.09 \\
\hline
\end{tabular}

NHLBI EVS, National Heart, Lung, and Blood Institute Exome Variant Server; ExAC, Exome Aggregation Consortium database (accessed February 2015). Variants in XPR1 currently explain about $5.5 \%$ of cases in the French cohort and $2.5 \%$ of cases in the North American cohort. Thus, XPR 1 mutations are less common than SLC2OA2 and PDGFB mutations but are more common than PDGFRB mutations. 
activity to various degrees, despite normal expression of the three phosphate transporters PiT1, PiT2 and XPR1 (Supplementary Fig. 4). Expression of XPR1 with the predicted non-damaging p.Lys53Arg substitution restored phosphate efflux to wild-type levels, making the causative role of this variant in PFBC uncertain.

After SLC20A2, XPR1 is the second PFBC-associated gene to encode a phosphate transporter. The presence of PFBC-causing mutations in SLC20A2 (PiT2) 2,3 suggests that inhibition of phosphate uptake may lead to deposition of calcium phosphate in the vascular extracellular matrix. In contrast, inhibition of phosphate export, associated with the XPR1 mutations, is expected to increase the intracellular phosphate concentration. Therefore, XPR1 mutation-mediated calcium phosphate precipitation is likely to occur intracellularly, as is characteristic of osteoblasts during bone mineralization ${ }^{15}$.

Phosphate import and export are interdependent functions that regulate intracellular phosphate homeostasis. However, it is not yet known whether XPR1 and PiT2 coregulate each other and/or are regulated by common factors. The PFBC-associated PDGFRB and PDGFB proteins, known to modulate phosphate transport, may also function as regulators of XPR1 and PiT2 levels in the brain ${ }^{5,6,16}$. PiT1 and PiT2 expression is modulated by the extracellular phosphate concentration $^{17}$, and we have recently reported that high-phosphate medium increases phosphate export whereas starvation decreases $\mathrm{it}^{13}$. It is therefore possible that alterations of PiT2-mediated phosphate transport might also alter XPR1-dependent phosphate export in areas of the brain where phosphate transporters are expressed ${ }^{18}$.

Five of the six XPR1 variants described in this study are clustered in the cytoplasmic N-terminal portion of XPR1 (Fig. 1a), and four lie in the SPX domain, which appears to be dispensable for intrinsic phosphate export activity ${ }^{13}$. A role of the SPX domain in protein trafficking may explain the retention of the Leu145Pro XPR1 mutant in cells. Interestingly, the corresponding substitution disrupts a dileucine motif known to be involved in protein endocytosis and plasma membrane trafficking ${ }^{19}$ that is highly conserved across evolution (Supplementary Fig. 5). The other mutants with impaired phosphate efflux activity were efficiently localized to the plasma membrane, suggesting function(s) other than trafficking for the SPX domain. Notably, the SPX domain was shown to modulate intracellular cyclic AMP (cAMP) levels, presumably through interactions with $G$ protein $\beta$ subunits ${ }^{20}$, although its role in phosphate regulation remains to be elucidated.

$X P R 1$ is actively expressed in neuronal stem cells ${ }^{13}$ and human brain ${ }^{10}$, and $X p r 1$ is expressed in several regions of the mouse brain (Allen Mouse Brain Atlas database; see URLs). Direct involvement of XPR1 in phosphate export and its expression pattern in brain support its role in cerebral phosphate homeostasis. These results identify $X P R 1$ as a new gene associated with PFBC and provide new insights into the role of phosphate homeostasis in PFBC etiology.

URLs. Allen Mouse Brain Atlas database, http://mouse.brain-map.org/; TOPO2 transmembrane protein display software, http://www.sacs.ucsf. edu/TOPO2/; dbSNP database, http://www.ncbi.nlm.nih.gov/SNP/; 1000 Genomes Project, http://www.1000genomes.org/; Exome Variant Server, http://evs.gs.washington.edu/EVS/; Exome Aggregation Consortium (ExAC), http://exac.broadinstitute.org/.

\section{METHODS}

Methods and any associated references are available in the online version of the paper.

Note: Any Supplementary Information and Source Data files are available in the online version of the paper.

\section{ACKNOWLEDGMENTS}

We acknowledge and thank all of the participants and families for their valuable contributions to our study; our clinical staff and laboratory members, J. DeYoung and the University of California Los Angeles (UCLA) Neuroscience Genomics Core, J. Touhami and J. Laval for their assistance and constant support; and the National Heart, Lung, and Blood Institute (NHLBI) GO Exome Sequencing Project and its ongoing studies, which produced and provided exome variant calls for comparison: the Lung GO Sequencing Project (HL-102923), the Women's Health Initiative (WHI) Sequencing Project (HL-102924), the Broad GO Sequencing Project (HL-102925), the Seattle GO Sequencing Project (HL-102926) and the Heart GO Sequencing Project (HL-103010). We are also indebted to the Montpellier Rio Imaging (MRI) platform for flow cytometry experiments. This work was funded by the US National Institutes of Health/National Institute of Neurological Disorders and Stroke (R01NS040752 to D.H.G.), by Association Française contre les Myopathies (AFM) and Ligue Nationale contre le Cancer (Comité de l'Hérault; to J.-L.B.), and by Fondation pour la Recherche Médicale (FRM) and a FEDER European Union Languedoc-Roussillon grant (Transportome; to M.S.). We also acknowledge the support of the National Institute of Neurological Disorders and Stroke Informatics Center for Neurogenetics and Neurogenomics (PSNS062691). D.G. was supported by FRM, Institut National du Cancer (INCa) and Labex GR-Ex (ANR-11-LABX-0051) fellowships, and U.L.-S. was supported by a Labex EpiGenMed (ANR-10-LABX-12-01) fellowship; Labex is funded by the program 'Investissements d'Avenir' of the French National Research Agency. J.-L.B. and M.S. were supported by INSERM. M.-J.S. and B.Q. are supported by the Fondo de Investigación Sanitaria, grant PI12/00742; INNOPHARMA project MINECO-USC; and FEDER funds. M.-J.S. and B.Q. hold research contracts from the Institute of Health Carlos III-SERGAS. J.R.M.O. acknowledges funding from FACEPE (APQ 1831-4.01/12) and CNPq (457556/2013-7; 480255/2013-0; 307909/2012-3). B.L.F. is funded by US National Institutes of Health grants K08MH086297 (National Institute of Mental Health) and R01NS082094 (National Institute of Neurological Disorders and Stroke). G.N., A.-C.R., D.H. and D.C. are supported by INSERM, the University Hospital of Rouen and the French CNR-MAJ.

\section{AUTHOR CONTRIBUTIONS}

M.S., D.H.G., J.-L.B. and G.C. designed the study. A.L., D.G., G.N. and U.L.-S. designed and performed experiments. A.L., D.G., G.N., U.L.-S., B.Q., J.R.M.O., L.S., E.M.R., E.S., M.-J.S., A.-C.R., D.C., M.S., D.H.G., J.-L.B. and G.C. analyzed data. A.L., D.G., M.S., J.-L.B. and G.C. wrote the manuscript. A.L., D.G., G.N., J.R.M.O., R.L.S., E.M.R., M.-J.S., B.L.F., A.E.L., Z.M., H.P., P. Striano, V.K.U., M.W.W., M.S., J.-L.B. and G.C. edited the manuscript. G.N., B.Q., J.R.M.O., E.S., M.-J.S., Á.C., C.C.-F., S.C., B.L.F., C.G., J.C.J., S.K., A.E.L., Z.M., W.M., M.P., H.P., J.P., N.S.S., S.A.S., P. Striano, P. Svenningsson, F.T., V.K.U., O.V., M.W.W., S.W., M.Y., F.B., D.H., D.H.G. and G.C. recruited and evaluated patients and collected blood samples.

\section{COMPETING FINANCIAL INTERESTS}

The authors declare competing financial interests: details are available in the online version of the paper.

Reprints and permissions information is available online at http://www.nature.com/ reprints/index.html.

1. Sobrido, M.J., Coppola, G., Oliveira, J., Hopfer, S. \& Geschwind, D.H. GeneReviews http://www.ncbi.nlm.nih.gov/books/NBK1421/ (2014).

2. Wang, K. et al. Nat. Genet. 44, 1098-1103 (2012).

3. Hsu, S.C. et al. Neurogenetics 14, 11-22 (2013).

4. Kavanaugh, M.P. et al. Proc. Natl. Acad. Sci. USA 91, $7071-7075$ (1994).

5. Nicolas, G. et al. Neurology $80,181-187$ (2013).

6. Keller, A. et al. Nat. Genet. 45, 1077-1082 (2013).

7. Boller, F. et al. J. Neurol. Neurosurg. Psychiatry 40, 280-285 (1977).

8. Oliveira, J.R. et al. Neurology 63, 2165-2167 (2004).

9. Battini, J.L. et al. Proc. Natl. Acad. Sci. USA 96, 1385-1390 (1999).

10. Tailor, C.S. et al. Proc. Natl. Acad. Sci. USA 96, 927-932 (1999).

11. Secco, D. et al. New Phytol. 193, 842-851 (2012).

12. Secco, D. et al. FEBS Lett. 586, 289-295 (2012).

13. Giovannini, D. et al. Cell Rep. 3, 1866-1873 (2013).

14. Wege, S. \& Poirier, Y. FEBS Lett. 588, 482-489 (2014).

15. Boonrungsiman, S. et al. Proc. Natl. Acad. Sci. USA 109, 14170-14175 (2012).

16. Kakita, A. et al. Atherosclerosis 174, 17-24 (2004).

17. Kavanaugh, M.P. \& Kabat, D. Kidney Int. 49, 959-963 (1996).

18. Lagrue, E. et al. J. Biomed. Sci. 17, 91 (2010).

19. Guo, Y. \& Jose, P.A. PLOS ONE 6, e29204 (2011).

20. Vaughan, A.E. et al. J. Virol. 86, 1661-1669 (2012). 


\section{ONLINE METHODS}

Patients. Patient enrollment. Seventeen individuals from one family were enrolled in this study through the University of California Los Angeles (UCLA) Medical Center after providing informed consent. The clinical features of this family were described in a previous report ${ }^{7}$. An additional 86 cases self-defined as Caucasian with a clinical diagnosis of idiopathic brain calcification (either sporadic or with family history of brain calcifications) and with no mutations in SLC20A2, PDGFB and PDGFRB were recruited at collaborating institutions. Some of these individuals were included in previous clinical or genetic studies (47 of them were recruited using inclusion criteria as previously described ${ }^{21}$ ). The study was approved by the UCLA Institutional Review Board. Patients gave informed, written consent for genetic analyses. Medical history was obtained and neurological examinations were performed for all probands and additional family members. Serum calcium and parathormone levels were assayed to exclude calcium dysregulation and other metabolic disorders that would cause brain calcifications unrelated to PFBC.

Neuroimaging. Head CT scans were performed as part of the diagnostic workup or were reviewed for the presence of calcifications or other brain abnormalities. Subjects with CT scans positive for calcifications were given an affected disease status, whereas patients with a negative CT scan who were $>50$ years of age and remained asymptomatic until their death were assigned an unaffected disease status. Subjects whose CT scans were negative but who were under the age of 50 years and subjects whose CT scan results were not available were classified as having unknown disease status.

Exome analysis. Genomic DNA was extracted from peripheral blood and fragmented by sonication, using the Covaris acoustic disruptor (E210, Covaris) to achieve an average fragment size of $200 \mathrm{bp}$. We used $1 \mu \mathrm{g}$ of DNA from each individual for the construction of a paired-end library. Exome capture was performed using the TruSeq DNA Sample Prep kit (Illumina).

Sequencing was performed on an Illumina Genome Analyzer HiSeq 2500 according to the manufacturer's instructions. We obtained 46.4 million 100base, paired-end reads per sample on average, with a $20 \times$ average depth of coverage within the targeted exome. Raw image files were processed with Illumina CASAVA 1.8 software. The sequencing reads were aligned to the NCBI human reference genome (GRCh37/hg19) using the Burrows-Wheeler Aligner (BWA). Variant calling was performed using the Genome Analysis Toolkit (GATK, version 2.6.4), and Qiagen Ingenuity Variant Analysis software was used for variant annotation and filtering. Filtering was carried out by applying a series of steps (Supplementary Fig. 1b): low-quality variants were filtered out using the Illumina Qscore threshold of 20; in addition, variants present in dbSNP138 and with a minor allele frequency (MAF) higher than $1 \%$ in the 1000 Genomes Project (see URLs) and Exome Variant Server (see URLs) databases were filtered out; finally, we focused on predicted missense, frameshift, stop-gain or stop-loss, and splice-site variants. The potential effect of the variants on protein function was assessed by PolyPhen-2, SIFT and MutationTaster. PolyPhen-2 is a software tool that predicts damaging effects by combining an evaluation of the properties of the mutated amino acid and the conservation of the residue ${ }^{22}$. SIFT is a tool developed to predict the deleterious effect of an amino acid substitution on the basis of sequence homology analysis ${ }^{23}$. MutationTaster is a web-based application that integrates information from several analysis tools. Disease potential is evaluated on the basis of evolutionary conservation, splice-site changes, loss of protein features and changes that might affect the amount of mRNA ${ }^{24}$. Residue conservation was evaluated using Genomic Evolutionary Rate Profiling (GERP), an algorithm that identifies constrained elements in multiple-sequence alignments by quantifying substitution deficits ${ }^{25}$. GERP score can range from -12.3 to 6.17 , with 6.17 corresponding to the most conserved elements. The protein schematic (Fig. 1a) was created using TOPO2 transmembrane protein display software (see URLs). Variant frequency was also checked in the ExAC database (accessed February 2015; see URLs), where XPR1 has a mean coverage of $65.2 \times$ (range: $41-206 \times$ ) across 115,519.9 alleles on average.
Sanger sequencing analysis. Sanger sequencing was initially performed to screen the genes already known to be associated with PFBC (SLC20A2, $P D G F R B$ and $P D G F B$ ) and to validate the variants identified through exome sequencing. Genomic DNA extracted from blood was used as template for PCR reactions to amplify the coding regions of SLC20A2 (NM_001257180.1), PDGFB (NM_002608.2) and PDGFRB (NM_002609.3), as well as that of XPR1 (NM_004736.3).

Cosegregation analysis. The maximum LOD score (recombination rate $=0$ ) was computed assuming an autosomal dominant pattern of inheritance and a penetrance of $100 \%$ at age 50 years (12 informative meioses fulfilling these criteria), according to the formula $Z(\theta)=\log \left((1-\theta)^{n-r} \theta^{r} /(1 / 2)^{n}\right)$, where $n$ is the total number of births, $r$ is the number of recombinant types and $\theta$ is the recombination rate.

Analysis of relatedness between the two families carrying the c.434T $>C$ XPR1 variant. We studied the genealogy of both families whose members included carriers of the c.434T >C (p.Leu145Pro) variant. We obtained data back to the 1750s in one branch of the French family (mother of the proband, known to be affected) and could not find any common ancestry with the North American family of Swedish descent. Furthermore, we compared exome sequencing data from all affected and unaffected individuals from the North American family in XPR1 and the surrounding genes on chromosome 1 and identified three variants (one downstream and two upstream of XPR1) that were present in the affected individual and absent in the unaffected individual: rs7536561 (529 kb from the XPR1 variant), rs79485039 (113 kb from the XPR1 variant) and rs 3747958 (125 $\mathrm{kb}$ from the XPR1 variant). We sequenced these SNPs in the proband of the French family who also carried the c.434T $>C$ (p.Leu145Pro) mutation and found reference sequences for all of them. This analysis supports the hypothesis that the mutation occurred on different haplotypes in the two families.

Cells. HEK293T (human embryonic kidney) and CHO hamster cells were cultured in DMEM supplemented with 10\% FBS (Invitrogen) and non-essential amino acids in a $5 \% \mathrm{CO}_{2}$ incubator at $37^{\circ} \mathrm{C}$ under humid atmosphere. For phosphate-free incubations, cells were grown in phosphate-free DMEM supplemented with $10 \%$ dialyzed FBS. Cells were obtained from the American Type Culture Collection. Cell lines in this study were free from mycoplasma contamination, as determined by monthly testing.

PBMCs were isolated from peripheral blood collected in the presence of heparin from both healthy donors and patients who had signed informed consent for research purposes. Blood samples were subjected to density gradient separation on Histopaque-1077 (1:1 ratio; Sigma-Aldrich) and centrifuged $24 \mathrm{~h}$ after blood collection. After centrifugation, the PBMC layer was collected and washed in DMEM before evaluation of phosphate efflux.

Plasmids and siRNAs. The mutations encoding p.Leu145Pro, p.Lys53Arg, p.Ser136Asn, p.Leu140Pro and p.Leu218Ser were generated by site-directed mutagenesis using recombinant PCR (details are available upon request). Sequences encoding HA-tagged versions of human XPR1 were introduced into both the pCHIX expression vector ${ }^{26}$ and the $\mathrm{PLXSN}$ retroviral vector ${ }^{27}$. The siRNA sequences (Integrated DNA Technologies) targeting the 3' UTR of human XPR1 were as follows: $5^{\prime}$-GGAUUUCAUGCCAUCCCAUTT- $3^{\prime}$ and 5'-GCACUUCCACCAUGUAUUATT- ${ }^{\prime}$ '. siRNA directed against the firefly luciferase gene was used as a control. HEK293T cells grown on six-well plates coated with poly(D-lysine) were transfected with 50 pmol of siRNA per well using the calcium phosphate method.

Phosphate flux in human cells. Phosphate uptake and efflux from HEK293T cell monolayers, transfected $2 \mathrm{~d}$ before assays, were measured as previously described ${ }^{9}$. Briefly, for uptake measurements, cells were incubated for 
$30 \mathrm{~min}$ at $37^{\circ} \mathrm{C}$ in phosphate-free DMEM supplemented with $0.5 \mu \mathrm{Ci} / \mathrm{ml}{ }^{33} \mathrm{P}$ (NEZ080500UC, PerkinElmer). Cell lysates were then assayed for radioactivity by scintillation counting and for protein content by the BCA protein assay (Pierce). The percentage of phosphate uptake was calculated as the ratio of cellular ${ }^{33} \mathrm{P}$ to the total amount of supplemented ${ }^{33} \mathrm{P}$. For the efflux measurements, cells were incubated for $20 \mathrm{~min}$ at $37^{\circ} \mathrm{C}$ in phosphate-free DMEM supplemented with $0.5 \mu \mathrm{Ci} / \mathrm{ml}^{33} \mathrm{P}$, gently washed three times with phosphate-free medium and then incubated in DMEM for $30 \mathrm{~min}$ at $37^{\circ} \mathrm{C}$ in $10 \mathrm{mM}$ phosphate before collection of the supernatant. The amount of ${ }^{33} \mathrm{P}$ in the supernatants and cell lysates was measured by liquid scintillation. The percentage of phosphate efflux was calculated as the ratio of released ${ }^{33} \mathrm{P}$ to total cellular ${ }^{33} \mathrm{P}$. Phosphate efflux in PBMCs was assayed as described above with $5 \times 10^{5}$ cells per assay.

Immunoblotting. Whole-cell extracts $(15 \mu \mathrm{g})$ were separated by $12 \%$ SDSPAGE under reducing conditions, transferred to PVDF membranes and probed with antibodies against HA (3F10, Roche Applied Science; 1:5,000 dilution) or $\beta$-actin (A5441, Sigma-Aldrich; 1:5,000 dilution). Proteins of interest were detected with horseradish peroxidase (HRP)-conjugated anti-mouse or anti-rat antibodies (1:5,000 dilution; SouthernBiotech) and visualized with the Pierce ECL western blotting substrate (Thermo Scientific), according to the manufacturer's protocol.

Flow cytometry. Cell surface expression of phosphate transporters was monitored on HEK293T cells with soluble ligands derived from the RBD of different Env proteins. XRBD, koala retrovirus (KoRV) RBD (KoRBD) and amphotropic-MLV RBD (ARBD) were used to detect XPR1, PiT1 and PiT2, respectively ${ }^{13,28}$. Binding assays were carried out as previously described ${ }^{13}$. Briefly, $5 \times 10^{5}$ cells were resuspended in $200 \mu \mathrm{l}$ of PBA (PBS with $2 \% \mathrm{FBS}$ and $0.1 \%$ sodium azide) containing the proper $\mathrm{RBD}$, incubated for $30 \mathrm{~min}$ at $37^{\circ} \mathrm{C}$, washed twice with PBA and incubated for $20 \mathrm{~min}$ at $4{ }^{\circ} \mathrm{C}$ with Alexa Fluor 488-conjugated anti-mouse IgG1 antibodies (1:500 dilution; Invitrogen). Cells were immediately analyzed on a FACSCalibur instrument (Becton Dickinson), and data analysis was performed using FlowJo software.

Virus production. LAPSN viral vectors were produced from $2 \times 10^{6} \mathrm{HEK} 293 \mathrm{~T}$ cells in 10-cm dishes cotransfected using the calcium phosphate method with an MLV-based LAPSN retroviral vector carrying the alkaline phosphatase reporter gene $\mathrm{e}^{29}(10 \mu \mathrm{g})$, the MLV Gag-Pol expression vector (pC57GPBEB;
$5 \mu \mathrm{g})^{30}$, and expression vectors for either vesicular stomatitis virus glycoprotein (VSV-G) or the X-MLV envelope (Env) glycoprotein ( $5 \mu \mathrm{g}$ ). Virion-containing media were collected $2 \mathrm{~d}$ later, filtered through a $0.45-\mu \mathrm{m}$ (pore size) filter and stored at $-80^{\circ} \mathrm{C}$ before use. LXSN viral vectors carrying wild-type or mutant $X P R 1$ were produced under the same conditions, except that the LAPSN retroviral vector was replaced by the various XPR1 LXSN vectors.

Viral infection and G418 selection. CHO cells stably expressing $X P R 1$ constructs were generated by transducing $\mathrm{CHO}$ cells with the pL(XPR1)SN, pL(XPR1K53R)SN, pL(XPR1S136N)SN, pL(XPR1L140P)SN, pL(XPR1L145P)SN and pL(XPR1L218S)SN vectors or with empty pLXSN vector and selecting cells the next day with medium containing $1.5 \mathrm{mg} / \mathrm{ml}$ G418 (active fraction). G418-resistant clones were pooled after 2 weeks of selection before further experiments.

CHO cells $\left(2 \times 10^{4}\right)$ stably expressing wild-type XPR1 or the Lys53Arg, Ser136Asn, Leu140Pro, Leu145Pro or Leu218Ser mutants from the MLV-based LXSN retroviral vector were plated in 12-well plates and infected the following day with serial dilutions of replication-defective LAPSN retroviral vector pseudotyped with the X-MLV Env or VSV-G glycoprotein. Cells were stained $2 \mathrm{~d}$ later for alkaline phosphatase expression, as previously described ${ }^{29}$, and alkaline phosphatase-positive colonies were counted to determine viral titers (colony forming units $(\mathrm{CFU}) / \mathrm{ml}$ ).

Statistical analysis. The Student's $t$ test in GraphPad Prism 5 software was used to calculate $P$ values, and the following convention was used: ${ }^{*} P \leq 0.05$; ${ }^{* *} P \leq 0.01 ;{ }^{* * *} P \leq 0.001 ;{ }^{* * *} P \leq 0.0001$.

21. Nicolas, G. et al. Brain 136, 3395-3407 (2013).

22. Adzhubei, I.A. et al. Nat. Methods 7, 248-249 (2010).

23. Ng, P.C. \& Henikoff, S. Genome Res. 11, 863-874 (2001).

24. Schwarz, J.M., Rödelsperger, C., Schuelke, M. \& Seelow, D. Nat. Methods 7, 575-576 (2010).

25. Cooper, G.M. et al. Genome Res. 15, 901-913 (2005).

26. Manel, N. et al. Cell 115, 449-459 (2003).

27. Miller, A.D. \& Rosman, G.J. Biotechniques 7, 980-982 (1989).

28. Petit, V. et al. Lab. Invest. 93, 611-621 (2013).

29. Miller, D.G., Edwards, R.H. \& Miller, A.D. Proc. Natl. Acad. Sci. USA 91, 78-82 (1994).

30. Lassaux, A., Sitbon, M. \& Battini, J.-L. J. Virol. 79, 6560-6564 (2005). 


\section{SUPPLEMENTARY FIGURES \\ AND TABLES}

a

।

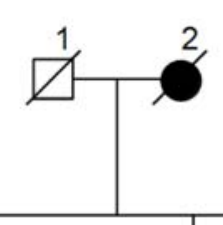

II

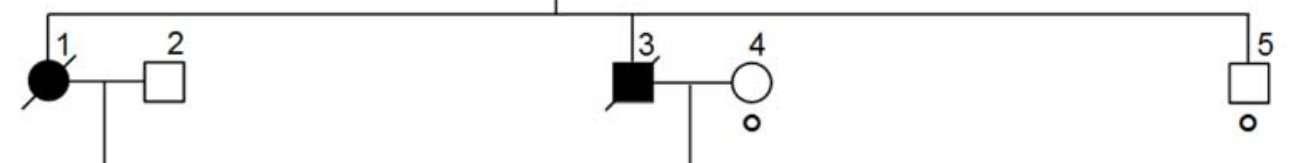

III

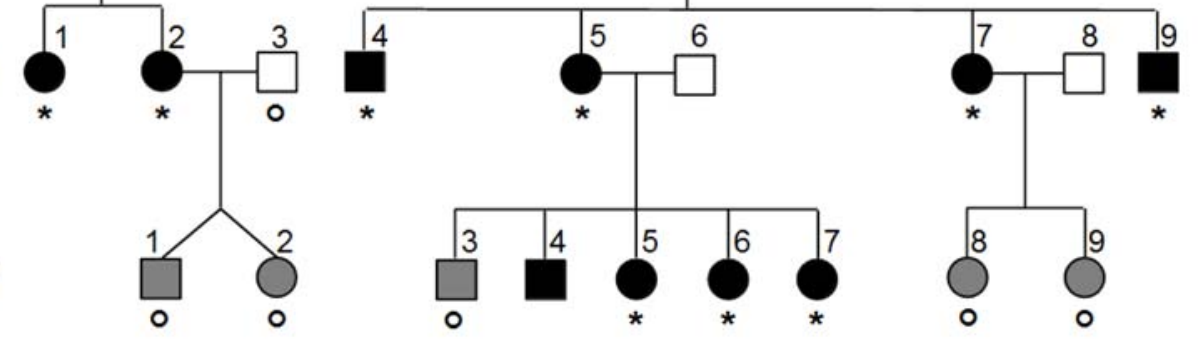

b

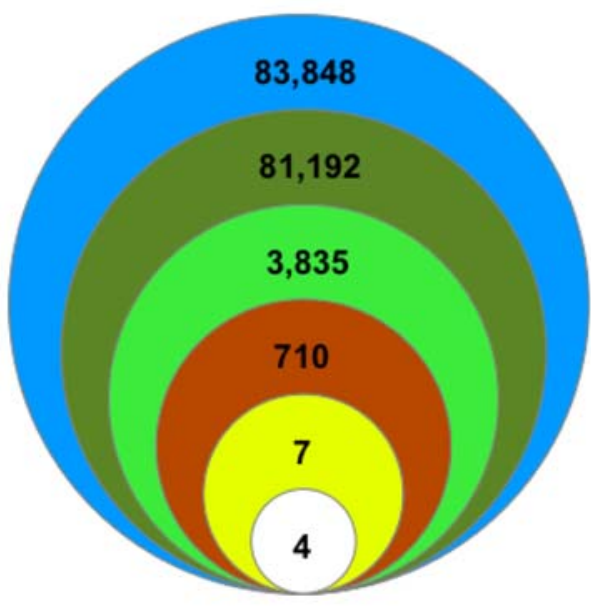

TOTAL VARIANTS

CONFIDENCE Q score $>20$

NOT IN dbSNP, MAF < $1 \%(1000 \mathrm{~g}$, ESP)

MISSENSE, STOP, SPLICING

SEGREGATING WITH DISEASE

PREDICTED DAMAGING

\section{Supplementary Figure 1}

Exome sequencing in five members of the PFBC family and identification of four candidate variants.\#

(a) Pedigree of the PFBC family. Shown are unaffected (open), affected (filled) and uncertain clinical state (gray) family members with homozygote reference sequence $(0)$ and heterozygote mutation $\left({ }^{*}\right)$. (b) Filtering of the variants identified by exome sequencing. 
Family FR-EXT-895
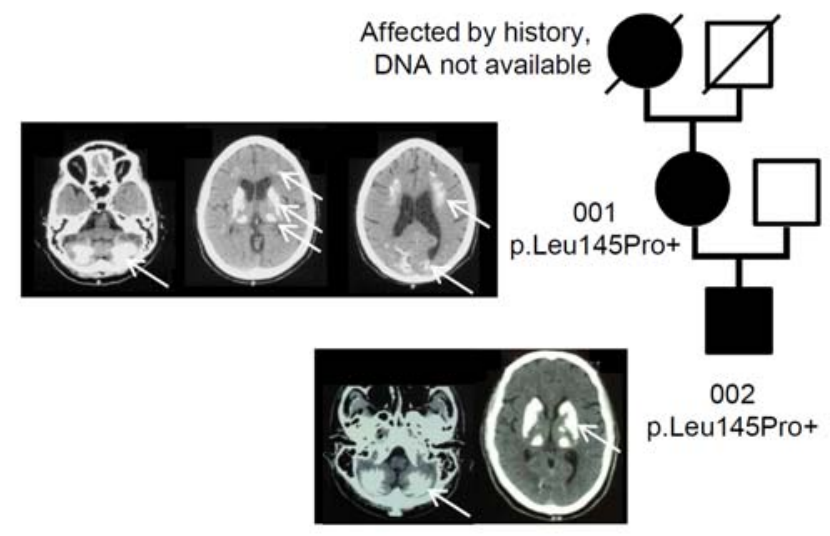

002

p.Leu145Pro+
Family FR-ROU-1025

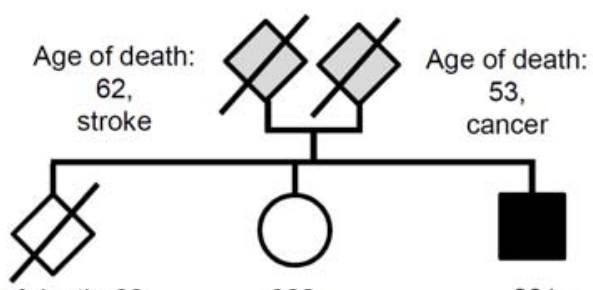

002

001

No pathological calcification XPR1 WT p.Ser136Asn+

DNA not available
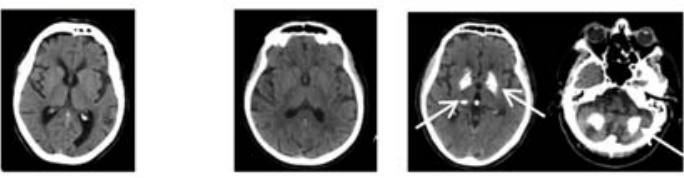

Family FR-EXT-955

Family FR-EXT-685

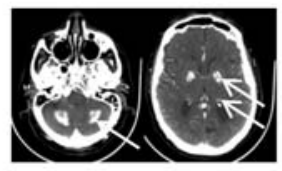

001

p.Leu140Pro+

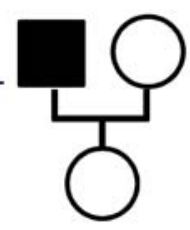

002

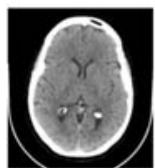

CT scan: no calcification

XPR1 WT

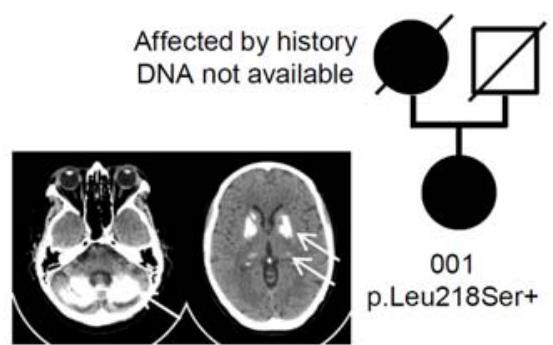

\section{Supplementary Figure 2}

Reduced pedigrees of French families with XPR1 variant carriers.

Affected individuals with pathological calcification, as visualized by computed tomography (CT) scan, are represented by solid symbols; open symbols represent individuals with CT scans showing no pathological calcification and gray symbols are used for individuals with unknown status (no available CT scan). With the exception of the parents of patient ROU-1025-001, only informative relatives are shown. When available, characteristic axial views of CT scans of patients and unaffected relatives are included next to the corresponding individual. White arrows indicate areas of brain calcification. 

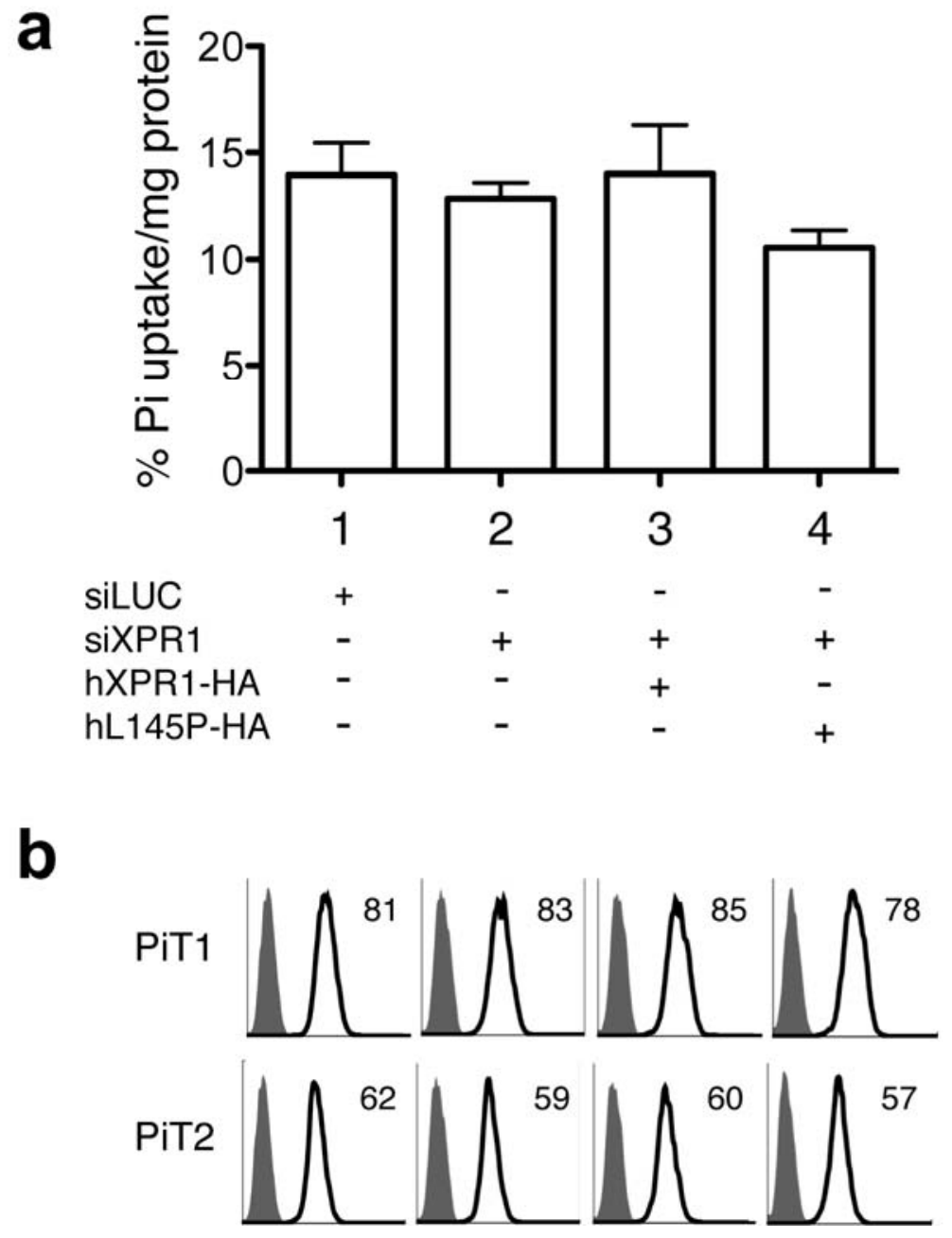

\section{Supplementary Figure 3}

XPR1 p.Leu145Pro alteration has no effect on phosphate uptake.

(a) Uptake of ${ }^{33} \mathrm{P}$ in HEK293T cells transfected as in Figure 2. Results are means \pm s.e.m. from a representative experiment $(n=3)$. (b) Cell surface expression of PiT1 (top) and PiT2 (bottom) as monitored by flow cytometry. Numbers correspond to the delta mean fluorescence values. Shown is a representative experiment $(n=3)$. 


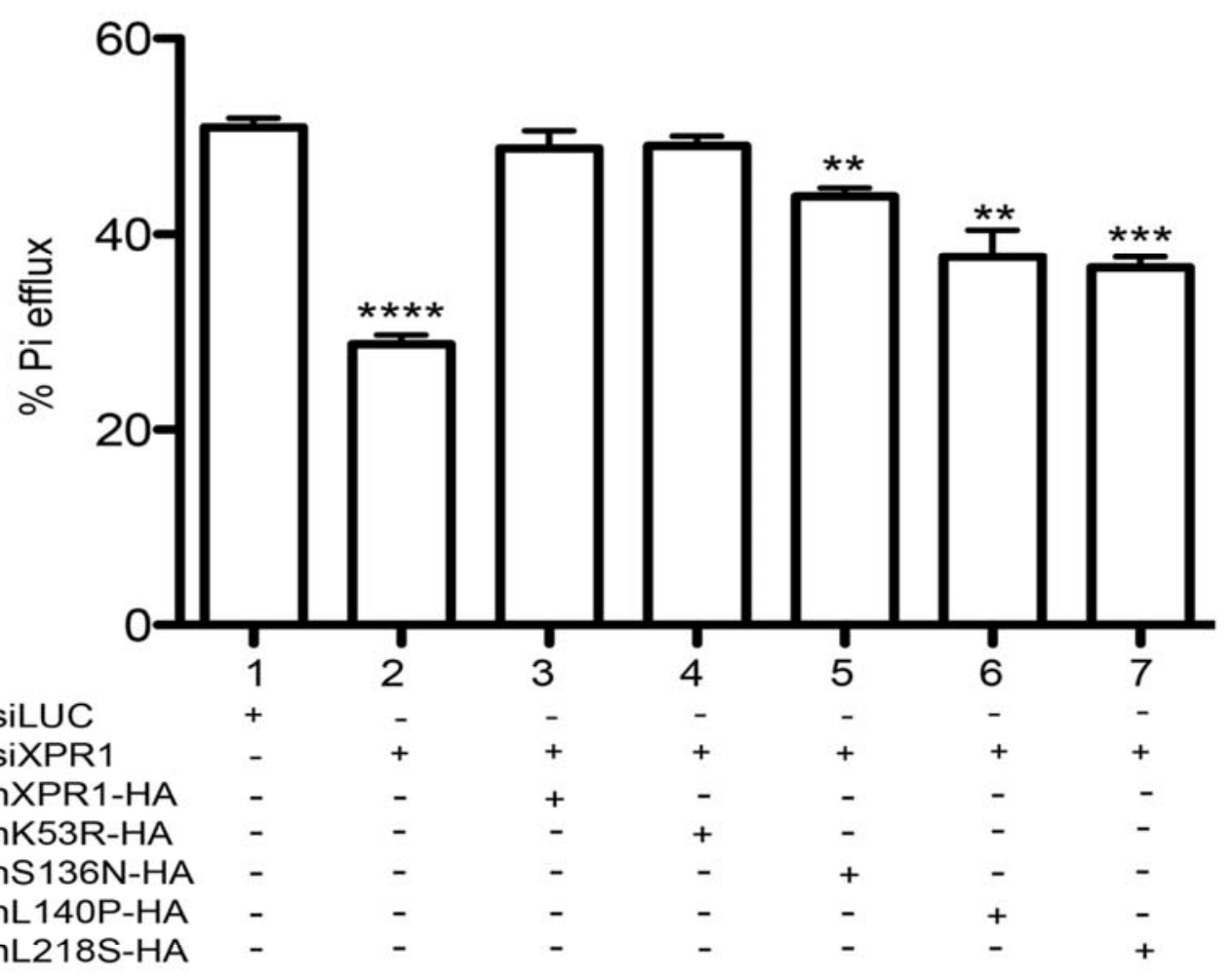

b

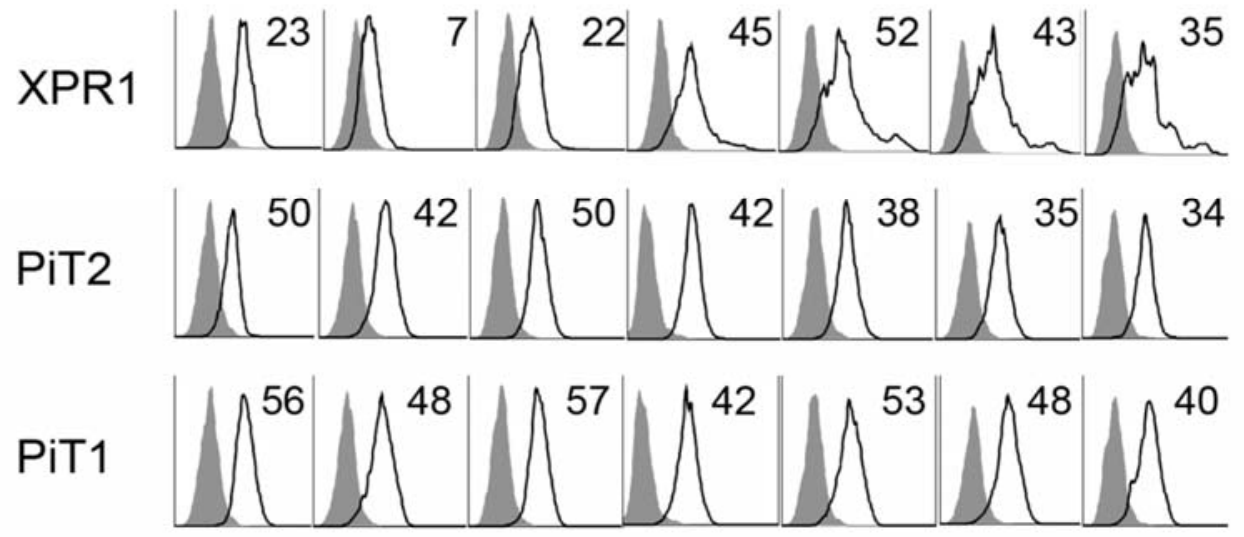

\section{Supplementary Figure 4}

Predicted damaging XPR1 mutants and not the p.Lys53Arg non-damaging mutant alter inorganic phosphate efflux.

(a) ${ }^{33} \mathrm{P}$ efflux in HEK293T cells transfected with siLUC (lane 1), siXPR1 alone (lane 2) or siXPR1 in combination with HA-tagged XPR1 expression vectors harboring either wild-type XPR1 (lane 3), the non-damaging p.Lys53Arg mutant (lane 4) or the damaging p.Ser136Asn (lane 5), p.Leu140Pro (lane 6) or p.Leu218Ser (lane 7) XPR1 mutants. Shown are means \pm s.e.m. $\left(n=3\right.$ ); ${ }^{\star} P<0.05$, ${ }^{\star \star} P$ $<0.01,{ }^{* * \star} P<0.001$, ${ }^{* * \star \star} P<0.0001$. (b) XPR1 (top), PiT2 (middle) and PiT1 (bottom) cell surface expression as monitored by flow cytometry using XRBD, AmphoRBD and KoRBD, respectively. Numbers represent the specific mean fluorescence intensity of one representative of three independent experiments. 
1 Homo sapiens

2 Felis_catus

3 Rattus_norvegicus

4 Mus musculus

5 Didelphis virginiana

6 Xenopus_laevis

7 Danio rerio

8 Drosophila melanogaster

1 Homo sapiens

2 Felis_catus

3 Rattus_norvegicus

4 Mus musculus

5 Didelphis_virginiana

6 Xenopus_laevis

7 Danio rerio

8 Drosophila_melanogaster

1 Homo sapiens

2 Felis catus

3 Rattus_norvegicus

4 Mus musculus

5 Didelphis virginiana

6 Xenopus_laevis

7 Danio_rerio

8 Drosophila melanogaster

1 Homo_sapiens

2 Felis catus

3 Rattus_norvegicus

4 Mus_musculus

5 Didelphis virginiana

6 Xenopus_laevis

7 Danio_rerio

8 Drosophila melanogaster

1 Homo sapiens

2 Felis_catus

3 Rattus_norvegicus

4 Mus musculus

5 Didelphis virginiana

6 Xenopus_laevis

7 Danio_rerio

8 Drosophila melanogaster

1 Homo_sapiens

2 Felis_catus

3 Rattus_norvegicus

4 Mus musculus

5 Didelphis_virginiana

6 Xenopus_laevis

7 Danio rerio

8 Drosophila melanogaster

1 Homo_sapiens

2 Felis catus

3 Rattus norvegicus

4 Mus_musculus

5 Didelphis_virginiana

6 Xenopus_laevis

7 Danio_rério

8 Drosophila_melanogaster

1 Homo_sapiens

2 Felis catus

3 Rattus_norvegicus

4 Mus_musculus

5 Didelphis virginiana

6 Xenopus_laevis

7 Danio_rerio

8 Drosophila melanogaster

1 Homo sapiens

2 Felis catus

3 Rattus_norvegicus

4 Mus musculus

5 Didelphis virginiana

6 Xenopus_laevis

7 Danio rerio

8 Drosophila melanogaster

Nature Genetics: doi:10.1038/ng.3289
1

53

作

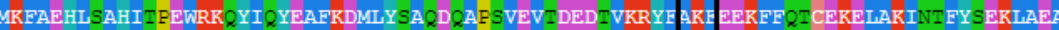

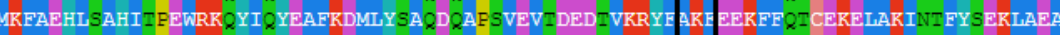

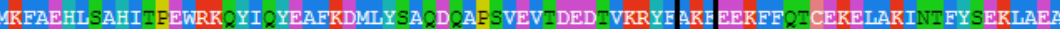

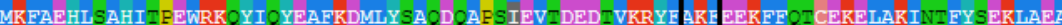

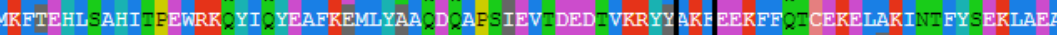

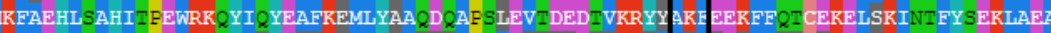
IKFAEHLSAHITPEWRKQY INYEBMRAMLYLAVEEAP SVESVEDDVLKRHF ANE DENFFHYCDKELKKINT FYSEKLAER

81

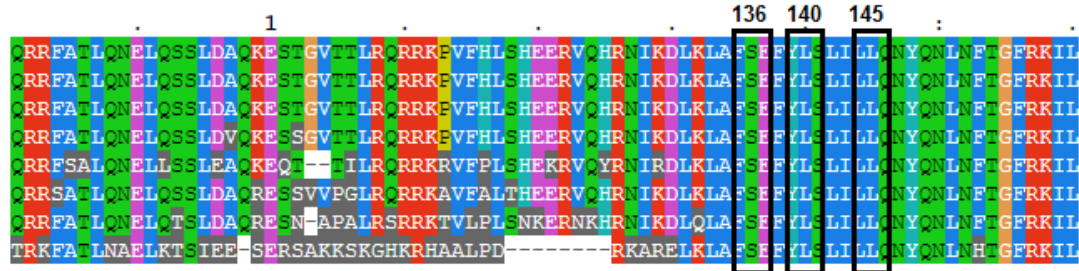

160

161

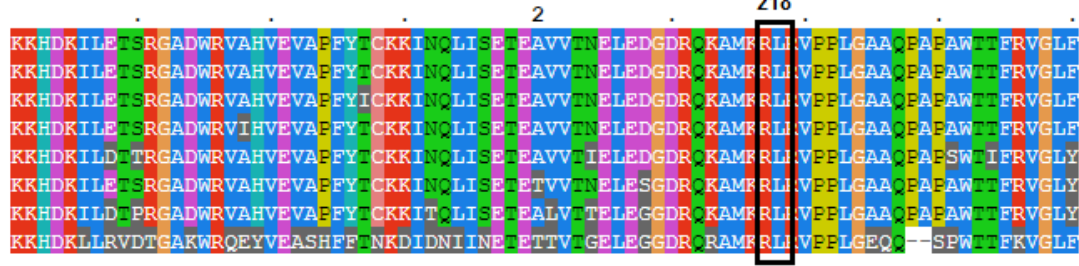

241

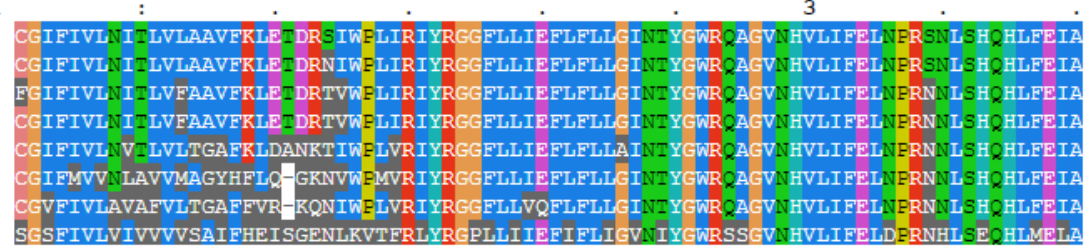

321

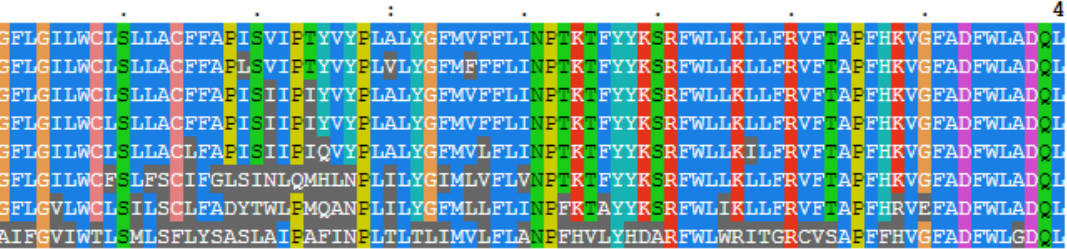

401

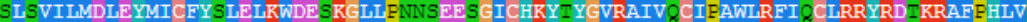

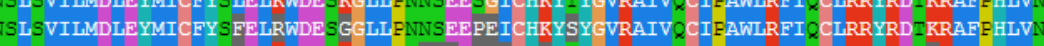
JSLSVI IMDIEYMI CFY SEELKWDESKGLL FNDPQEPEFCHGYTYGVRAIVQCI PAWLREIQCLRRYRDTRRAEPHLVN TSLSVI IMDLEYMI CFY SFELKWDESKGLL FNDPQEPEFCHKYSYGVRAIVQC I PAWLREI $Q_{Q} C L R R Y R D T R R A F P H L V N$ SLTVLIMDLEYMI CEY SEELKWDESKGLLPDKTGGPDICYSYIYGVRAIVQCI PAWLREI QCIRRYRDTKRPEPHLAN

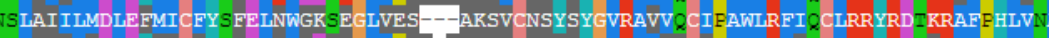
NSLVIVLSDIEYLVCYYSMELQWGERN GLLFAK-EGDERCNSFSYGVRAI I HCL PAWLREV $Q$ CLRRYRD TRRAEPHLVN NSLATAILDEEYLICEYETNGNWTEAR-------DAS ICMIKDEI IRPIVNCLFAWEREAQCLRRYRDSREAEPHLVNA

481

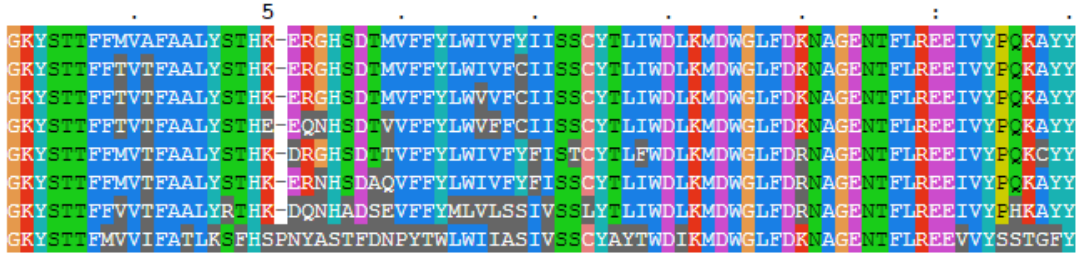

560

561

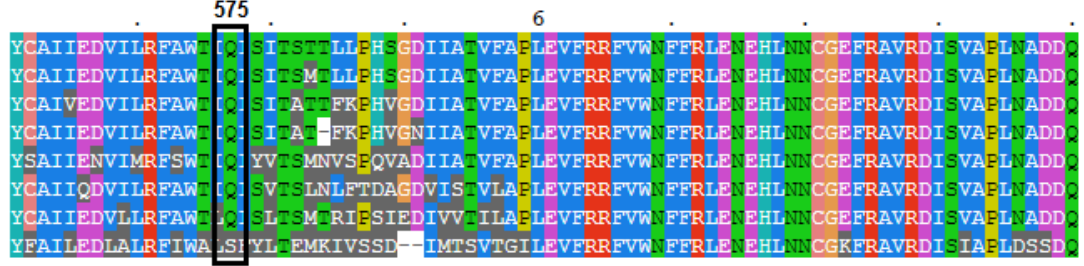

640

641
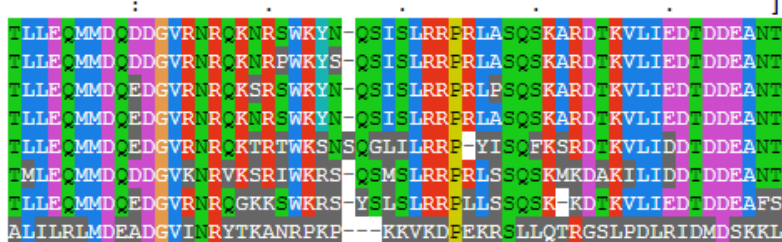

] 698 


\section{Supplementary Figure 5}

\section{Multiple-sequence alignment of orthologous XPR1 proteins from different species.}

Multiple alignment of the amino acid sequence of human XPR1 (NP_004727.2) with the orthologous proteins of Felis catus (XP_011289290.1), Rattus norvegicus (NP_001099462.1), Mus musculus (NP_035403.1), Didelphis virginiana (AHI85562.1), Xenopus laevis (NP_001086930.1), Danio rerio (NP_001232029.1) and Drosophila melanogaster (XP_001977625.1) performed with ClustalW2. Residues that differ from human XPR1 are shown in gray, and different colors indicate hydrophobic (AFILMVW; blue), basic (KR; red), acidic (DE; magenta), or large and aromatic (HY; light blue) residues, while disulfide bonding (C; salmon), flexible (G; orange) and rigid (P; yellow) residues are singled out and other polar residues are grouped (NQST; green). The positions of residues altered by mutations identified in this study are boxed. 
Supplementary Table 1. Clinical And Laboratory Features As Available For 18 Family Members, Including 11 Affected Patients.

\begin{tabular}{|c|c|c|c|c|c|}
\hline $\begin{array}{l}\text { Pedigree } \\
\text { code }\end{array}$ & $\begin{array}{c}\text { DNA } \\
\text { Available }\end{array}$ & $\begin{array}{c}\text { Age at } \\
\text { examination }\end{array}$ & Clinical findings & CT Scan & Status \\
\hline II-1 & No & 43 & Slurred speech & Positive & Affected \\
\hline II-4 & Yes & 68 & asymptomatic & Negative & Unaffected \\
\hline II-5 & Yes & 63 & asymptomatic & Negative & Unaffected \\
\hline III-1 & Yes & NA & NA ("nervous") & Positive & Affected \\
\hline III-2 & Yes & NA & asymptomatic & Positive & Affected \\
\hline III-4 & Yes & 47 & $\begin{array}{c}\text { onset at 44, severely affected, bedridden, speech } \\
\text { impairment, seizures. }\end{array}$ & Positive & Affected \\
\hline III-5 & Yes & 46 & $\begin{array}{l}\text { concentration and memory complaints; no neuro exam } \\
\text { available }\end{array}$ & Positive & Affected \\
\hline III-7 & Yes & 44 & $\begin{array}{l}\text { severe alcoholism, ataxia, tremor, eye movement } \\
\text { abnormalities }\end{array}$ & Positive & Affected \\
\hline III-9 & Yes & 40 & NA & Positive & Affected \\
\hline IV-1 & Yes & 19 & asymptomatic & Negative & Unknown \\
\hline IV-2 & Yes & 19 & asymptomatic & Negative & Unknown \\
\hline IV-3 & Yes & 14 & asymptomatic & Negative & Unknown \\
\hline IV-4 & No & 26 & $\begin{array}{l}\text { behavioral problems (anger outbursts), history of drug } \\
\text { abuse, tics }\end{array}$ & Positive & Affected \\
\hline IV -5 & Yes & 16 & asymptomatic & Positive & Affected \\
\hline IV-6 & Yes & 20 & asymptomatic & Positive & Affected \\
\hline IV-7 & Yes & 28 & seizures, depression & Positive & Affected \\
\hline IV-8 & Yes & 24 & asymptomatic & Negative & Unknown \\
\hline IV-9 & Yes & 18 & asymptomatic & Negative & Unknown \\
\hline
\end{tabular}


Supplementary Table 2. Variants Co-Segregating With Disease in Five Samples Studied With Exome Sequencing.

\begin{tabular}{|c|c|c|c|c|c|c|c|c|c|c|c|}
\hline $\begin{array}{l}\text { Genomic } \\
\text { Position }\end{array}$ & $\begin{array}{c}\text { Ref } \\
\text { Allele }\end{array}$ & $\begin{array}{l}\text { Sample } \\
\text { Allele }\end{array}$ & $\begin{array}{c}\text { Gene } \\
\text { Symbol }\end{array}$ & $\begin{array}{c}\text { Translation } \\
\text { Impact }\end{array}$ & $\begin{array}{c}\text { Protein } \\
\text { variation }\end{array}$ & $\begin{array}{c}\text { SIFT } \\
\text { Function } \\
\text { Prediction }\end{array}$ & $\begin{array}{c}\text { PolyPhen-2 } \\
\text { Function } \\
\text { Prediction } \\
\end{array}$ & $\begin{array}{l}\text { dbSNP } \\
\text { ID }\end{array}$ & $\begin{array}{c}\text { 1KGP } \\
\text { Frequency }\end{array}$ & $\begin{array}{l}\text { NHLBI EVS } \\
\text { Frequency }\end{array}$ & $\begin{array}{c}\text { ExAC } \\
\text { Allelic } \\
\text { Frequency }\end{array}$ \\
\hline chr1:44069518 & G & A & PTPRF & missense & p.G890S & Damaging & Probably Damaging & - & absent & absent & $0.0033 \%$ \\
\hline chr1:77685027 & A & G & PIGK & missense & p.S21P & Tolerated & Benign & - & absent & absent & $0.0016 \%$ \\
\hline chr1:180772734 & $\mathrm{T}$ & $\mathrm{C}$ & $X P R 1$ & missense & p.L145P & Damaging & Probably Damaging & - & absent & absent & absent \\
\hline chr8:145112410 & $\mathrm{T}$ & $\mathrm{C}$ & OPLAH & missense & p.M455V & Tolerated & Possibly Damaging & - & absent & absent & $0.0031 \%$ \\
\hline chr9:33798075 & $\mathrm{T}$ & $\mathrm{C}$ & PRSS3 & missense & p.F143S & Tolerated & Benign & - & absent & absent & absent \\
\hline chr10:91144371 & $\mathrm{T}$ & $\mathrm{C}$ & IFIT1B & missense & p.V434A & Tolerated & Benign & - & absent & absent & absent \\
\hline chr16:18870442 & $\mathrm{T}$ & $\mathrm{C}$ & SMG1 & missense & p.T1339A & Tolerated & Possibly Damaging & - & absent & absent & absent \\
\hline
\end{tabular}

1KGP: 1000 Genomes Project (http://www.1000genomes.org/)

NHLBI EVS: NIH Heart, Lung, and Blood Institute Exome Variant Server (EVS, http://evs.gs.washington.edu/EVS/)

ExAC: Exome Aggregation Consortium database, Cambridge, MA (URL: http://exac.broadinstitute.org) [accessed February 2015] 
Supplementary Table 3. Clinical Findings In Patients From The French PFBC Case Series With XPR1 Novel Missense Variants. The status is determined based on CT scan results. The individuals with pathological calcifications are considered as affected, the individuals with a normal CT scan are considered either as unaffected (if aged more than 50 years), or with an unknown status (if aged less than 50 years). In clinical findings column, ages are those when the first neuropsychiatric sign was noted (ages at onset).

\begin{tabular}{|c|c|c|c|c|c|c|}
\hline Code & Mutation & Ethnicity & Clinical findings & CT scan & \begin{tabular}{|l|} 
Status \\
\end{tabular} & Family History \\
\hline $\begin{array}{l}\text { FR-EXT-895 } \\
\text { Ind } 001\end{array}$ & $\begin{array}{l}\text { c.434T }>C, \\
\text { p.Leu145Pro }\end{array}$ & $\begin{array}{l}\text { Caucasian } \\
\text { (French) }\end{array}$ & $\begin{array}{l}63 \text { years: visual hallucinations, then } \\
\text { progressive gait disorder, Parkinsonism, } \\
\text { orofacial dyskinesia (possibly iatrogenic) } \\
\text { [+Left hemiparesis due to stroke related to } \\
\text { atrial fibrillation] }\end{array}$ & $\begin{array}{l}\text { Positive: } \\
\text { Striatum, pallidum, } \\
\text { thalamus, cerebellar } \\
\text { hemispheres, vermis, } \\
\text { subcortical white matter, } \\
\text { cortex }\end{array}$ & Affected & $\begin{array}{l}\text { Autosomal } \\
\text { dominant } \\
\text { (proband) }\end{array}$ \\
\hline $\begin{array}{l}\text { FR-EXT-895 } \\
\text { Ind } 002\end{array}$ & $\begin{array}{l}\text { c.434T }>C \text {, } \\
\text { p.Leu145Pro }\end{array}$ & $\begin{array}{l}\text { Caucasian } \\
\text { (French) }\end{array}$ & $\begin{array}{l}\text { Recurrent depression since age } 43 . \\
\text { Dysarthria. }\end{array}$ & $\begin{array}{l}\text { Positive: } \\
\text { Striatum, pallidum, } \\
\text { thalamus, cerebellar } \\
\text { hemispheres, vermis, } \\
\text { subcortical white matter, } \\
\text { cortex }\end{array}$ & Affected & $\begin{array}{l}\text { Autosomal } \\
\text { dominant } \\
\text { (son of 001) }\end{array}$ \\
\hline $\begin{array}{l}\text { FR-ROU-1025 } \\
\text { Ind } 001\end{array}$ & $\begin{array}{l}\text { c.407G>A, } \\
\text { p.Ser136Asn }\end{array}$ & $\begin{array}{l}\text { Caucasian } \\
\text { (French) }\end{array}$ & $\begin{array}{l}56 \text { years: progressive dysarthria } \\
\text { (cerebellar), mild cognitive impairment } \\
\text { (dysexecutive signs), behavioral } \\
\text { dysexecutive syndrome }\end{array}$ & $\begin{array}{l}\text { Positive: } \\
\text { Striatum, pallidum, } \\
\text { thalamus, cerebellar } \\
\text { hemispheres, vermis, } \\
\text { subcortical white matter, } \\
\text { cortex }\end{array}$ & Affected & $\begin{array}{l}\text { Sporadic } \\
\text { presentation } \\
\text { (censoring effect } \\
\text { in both parents) }\end{array}$ \\
\hline $\begin{array}{l}\text { FR-ROU-1025 } \\
\text { Ind } 002\end{array}$ & Exon $4 \mathrm{WT}$ & $\begin{array}{l}\text { Caucasian } \\
\text { (French) }\end{array}$ & NA & $\begin{array}{l}\text { Negative: no pathological } \\
\text { calcification }\end{array}$ & Unaffected & $\begin{array}{l}\text { Older sister of } \\
001 \text { (79 years) }\end{array}$ \\
\hline $\begin{array}{l}\text { FR-EXT-685 } \\
\text { Ind } 001\end{array}$ & $\begin{array}{l}\text { c.653T }>C, \\
\text { p.Leu218Ser }\end{array}$ & $\begin{array}{l}\text { Caucasian } \\
\text { (French) }\end{array}$ & 56 years : Mild cognitive impairment & $\begin{array}{l}\text { Positive: } \\
\text { Striatum, pallidum, } \\
\text { thalamus, cerebellar } \\
\text { hemispheres, vermis }\end{array}$ & Affected & $\begin{array}{l}\text { Autosomal } \\
\text { dominant } \\
\text { (Mother affected } \\
\text { by history: } \\
\text { cognitive } \\
\text { impairment, } \\
\text { Parkinsonism, } \\
\text { positive CT scan } \\
\text { (DNA not }\end{array}$ \\
\hline
\end{tabular}




\begin{tabular}{|l|l|l|l|l|l|}
\hline & & & & & available) \\
\hline $\begin{array}{l}\text { FR-EXT-955 } \\
\text { Ind 001 }\end{array}$ & $\begin{array}{l}\text { c.419T>C, } \\
\text { p.Pro140Leu }\end{array}$ & $\begin{array}{l}\text { Caucasian } \\
\text { (French) }\end{array}$ & $\begin{array}{l}\text { 73 years : one loss of consciousness } \\
\text { (seizure?), then progressive behavioral } \\
\text { troubles, akinetic-hypertonic syndrome, } \\
\text { cognitive impairment (dysexecutive } \\
\text { syndrome, visuoconstructive apraxia), sleep } \\
\text { movement disorder }\end{array}$ & $\begin{array}{l}\text { Positive: } \\
\text { Striatum, pallidum, } \\
\text { cerebellar hemispheres }\end{array}$ & $\begin{array}{l}\text { Affected } \\
\text { presentation }\end{array}$ \\
\hline $\begin{array}{l}\text { FR-EXT-955 } \\
\text { Ind 002 }\end{array}$ & Exon 4 WT & $\begin{array}{l}\text { Caucasian } \\
\text { (French) }\end{array}$ & NA & $\begin{array}{l}\text { Negative: no pathological } \\
\text { calcification }\end{array}$ & Unknown \\
\hline
\end{tabular}


Supplementary Table 4. XPR1 p.Leu145Pro Mutant Is Unable To Mediate XenotropicMurine Leukemia Virus Infection.

\begin{tabular}{lccccccc}
\hline & \multicolumn{5}{c}{ Infectious titer (cfu/ml) on } \\
& \multicolumn{7}{c}{ CHO cells expressing human XPR1 receptor variants } \\
\cline { 2 - 8 } Env & None & Wild type & p.Lys53Arg & p.Ser136Asn & p.Leu140Pro & p.Leu145Pro & p.Leu218Ser \\
\hline Xenotropic & $<10$ & $2.5 \times 10^{5}$ & $2.5 \times 10^{5}$ & $2.3 \times 10^{5}$ & $1.6 \times 10^{5}$ & 90 & $2.1 \times 10^{5}$ \\
VSV & $2 \times 10^{6}$ & $2.2 \times 10^{6}$ & $1.8 \times 10^{6}$ & $2.1 \times 10^{6}$ & $1.8 \times 10^{6}$ & $1.9 \times 10^{6}$ & $2.5 \times 10^{6}$ \\
\hline
\end{tabular}

CHO hamster cells stably expressing either of the wild-type or variant (p.Lys53Arg, p.Ser136Asn, p.Leu140Pro, p.Leu145Pro or p.Leu218Ser) XPR1, or with no additional receptor (None), were generated by transduction with LXSN retroviral vectors carrying the various XPR1 mutants and after selection with $1.5 \mathrm{mg}$ per $\mathrm{ml}$ of G418. Transduced G418resistant $\mathrm{CHO}$ cells were then assayed for infection with retroviral vectors pseudotyped with the indicated envelope glycoprotein (Env). Two days after infection, cell monolayers were stained for alkaline phosphatase expression. Titers, determined as colony forming units per $\mathrm{ml}(\mathrm{cfu} / \mathrm{ml})$, are average values from 3 different wells in one representative experiment $(\mathrm{n}=3)$. 


\section{Supplementary References}

21. Nicolas, G. et al. P Brain 136, 3395-407 (2013).

22. Adzhubei, I. A. et al. Nat. Methods 7, 248-249 (2010).

23. Ng, P. C. \& Henikoff, S. Genome Res. 11, 863-874 (2001).

24. Schwarz, J. M., Rödelsperger, C., Schuelke, M. \& Seelow, D. Nat. Methods 7, 575-6 (2010).

25. Cooper, G. M. et al. Genome Res. 15, 901-13 (2005).

26. Manel, N. et al. Cell 115, 449-59 (2003).

27. Miller, A. D. \& Rosman, G. J. Biotechniques 7, 980-2, 984-6, 989-90 (1989).

28. Petit, V. et al. Lab. Invest. 93, 611-21 (2013).

29. Miller, D. G., Edwards, R. H. \& Miller, A. D. Proc. Natl. Acad. Sci. USA. 91, 78-82 (1994).

30. Lassaux, A., Sitbon, M. \& Battini, J.-L. J. Virol. 79, 6560-4 (2005). 